\section{Autonomy and Capacity in Transi- tional Age Youth (TAY) with Serious Mental Illness: Challenges in Mental Health - A Case Report}

\author{
Andrea P Mendiola Iparraguirre ${ }^{1}$ and Timothy van Deusen ${ }^{1-4 *}$ \\ ${ }^{1}$ Department of Psychiatry, Connecticut Mental Health Center, Yale School of \\ Medicine, New Haven, USA \\ ${ }^{2}$ Assistant Professor of Psychiatry and in the Child Study Center, USA \\ ${ }^{3}$ Young Adult Service Yale School of Medicine, Connecticut, USA \\ ${ }^{4}$ West Haven Mental Health Clinic, West Haven, USA
}

\begin{abstract}
Objective: An admission to a medical or psychiatric inpatient unit is a difficult time during a Transitional Age Youth (TAY)'s life. While some patients recognize the need for their admission, severely ill patients lack insight into their illnessand require involuntary hospitalization, which may impactthe patient's quality of care, patient-doctor relationship and raise legal and ethical questions to patient's autonomy, capacity, and their wishes.
\end{abstract}

Methods: Describe the legal and ethical challenges of TAY with serious mental illness and multiple physical illnesses; illustrated by a clinical case.

Results: TAYis affected by legal issues involved with treatment in this population, including a patient's right to refuse treatment, involuntary commitment versus court-ordered treatment, advance directives, health care proxies, and confidentiality.

Conclusions: It is critical to recognize the ethical and legal issues encountered by TAY with serious mental illness. Understanding these matters will improvethe provider's care and enhance their ability to advocate for patients' rights.

Keywords: Autonomy; Capacity; Transitional Age Youth, Young Adult

*Corresponding author: Timothy van Deusen, Department of Psychiatry, Connecticut Mental Health Center, Yale School of Medicine. New Haven, USA, Tel: +1 2039745907; E-mail: timothy.vandeusen@yale.edu

Citation: Iparraguirre APM, Deusen van T (2019) Autonomy and Capacity in Transitional Age Youth (TAY) with Serious Mental Illness: Challenges in Mental Health - A Case Report. J Clin Stud Med Case Rep 6: 077.

Received: December 09, 2019; Accepted: December 17, 2019; Published: December 23, 2019

Copyright: (C) 2019 Iparraguirre APM, et al. This is an open-access article distributed under the terms of the Creative Commons Attribution License, which permits unrestricted use, distribution, and reproduction in any medium, provided the original author and source are credited.

\section{Previous Presentation}

Authors have presented some data relevant to this paper at the American Academy of Child and Adolescent Psychiatry (AACAP) 2019 Annual Meeting.

\section{Highlights}

- About $75 \%$ of all psychiatric illnesses occur by age 24; early intervention in TAY (16-25 years old) is critical in this vulnerable population

- Physicians play a significant role in assessing capacity, providing advice, guidance and support to the surrogate, conservator or judicial authorities

- Autonomy and capacity are complex topics in general and applying them to TAY carries multifaceted challenges that will be encountered mainly during involuntary admissions, decompensation due to medication non-adherence and refusal to accept treatments

\section{Introduction}

Studies have shown that there is a high prevalence in new-onset serious mental illness during late adolescence through early adulthood. If including the persistence of childhood disorders, about $75 \%$ of all psychiatric illnesses occur by age 24 [1]. Multiple lines of evidence suggest that intervention during this transitional age is critical when most high-prevalence disorders such as mood, anxiety, substance use and psychotic disorders emerge [2-4]. Theirdata indicates that a delay in the start of treatment can result in multiple deleterious consequences [2]. Therefore, prevention and early intervention are unquestionably the keys to reducing the burden of disease among children, adolescents and young people [2].

The transition in care for the Young Adult or Transitional Age Youth (TAY) population - usually defined as between ages 16 to 25 years old - has been characterized as challenging in both physical and mental health care [5]. Reaching the age of majority (18 years old) implies an increase in independent behavior and personal autonomy [6], which has significant implications for medical and mental health treatment choices. In a longitudinal cohort study by McMillen, et al., 325 young adults between ages 17 to 19 were interviewed about their use of mental health services. They showed that comparing the services received as minors versus 18 years old, that $11 \%$ continued receiving mental health services, and only $19 \%$ of patients continued taking their prescribed psychotropic medications [5]. The primary reasons for stopping medications were "not liking to be on medications" or "thinking that they do not need them" [5]. Studies have shown that once youth understand they have achoice, not the parent's, case manager's or foster parents, they tend to stop taking their medications; this is consistent with research with young people in the foster care system which showeddissatisfaction with the way their psychotropic medications were prescribed [7]. 
TAYs are in a critical period for treatment interventions. They can exercise their autonomy concerning treatment decision-making, which opens up ethical and legal challenges for clinicians working with this vulnerable population. The authors report a case that highlights these issues in a young adult with serious mental illness and multiple medical comorbidities. Some of the demographic information has been altered to protect the patient's autonomy; we will name the patient " $\mathrm{K}$ " for the same reasons.

\section{Case History}

\section{Current presentation}

$\mathrm{K}$ is a 24-year-old young adult male, single, previously homeless, unemployed, supported by Social Security Income (SSI), with a psychiatric diagnosis of schizoaffective disorder, bipolar type, and substance usedisorder (cocaine, marijuana, K2, LSD, alcohol) and with a medical history significant for asthma.

K presented to the Emergency Room (ER) in July of 2018 with persecutory delusions in the context of medication non-adherence (valproic acid and chlorpromazine) and was admitted for a month on the psychiatric inpatient unit. He was re-started on his medications and discharged to his family with the plan of resuming care with his outpatient program. Five days after K's discharge, he voluntarily returned to the ER seeking help after he had stopped all his medications and had been using alcohol and other substances. He presented with psychosis, mainly paranoia, word salad and florid neologisms. A full medical workup was conducted, including brain images, electroencephalograms, and inflammatory markers, and these studies did not show any abnormality. Clozapine was added to his medications and an application for Conservatorship was considered as his extended family could no longer care for him due to his non-adherence to medications and his chaotic, dangerous behaviors. The Conservatorship application was not completed since $\mathrm{K}$ demanded his discharge, and since he was admitted under voluntary status, he was discharged to a transitional living facility. At this new residential facility, K continued to abuse substances and stopped taking his psychiatric medications as well as medicines for diabetes, hypertension and asthma. A week later, $\mathrm{K}$ was readmitted to the hospital for medical issues requiring treatment in an Intensive Care Unit (ICU), diagnosed with diabetic ketoacidosis and necrotizing pancreatitis. During this hospitalization, he was admitted to the medical unit and received psychiatric care from the Consultation and Liason team. It was considered K's capacity to consent for surgical drainage of pancreatic abscesses, anticoagulation therapy and treatment, in general, was intact, yet refused his psychiatric medications. $\mathrm{K}$ agreed with all medical treatment recommendations and made decisions for his health and disposition plan; however, he continued to have persecutory delusions and prominent thought disorganization, which included word salad and neologisms. Once medically stable, $\mathrm{K}$ was transferred to a psychiatric inpatient unit and a few weeks later to a psychiatric state hospital under voluntary status for a prolonged admission. He is currently receiving clozapine and ECT with only partial remission of his symptoms. K's psychiatrist has recommended that a conservator be appointed for assistance with medical decision making and a representative payee for the administration of his finances and benefits.

\section{Past psychiatric history}

K's psychiatric issues started around age 15 at the same time, he started using alcohol and other substances. His main symptoms were psychosis and mania. He had attempted suicide multiple times via overdose of his medications or by the ingestion of toxic substances. The most dangerous attempts were in September 2010 and October 2011, where he jumped off of an over pass bridge on the interstate highway resulting in multiple fractures that caused chronic back and bilateral ankle pain. $\mathrm{K}$ started receiving services at a community-based outpatient program with wrap around services for young adults in 2011 . K received multiple trials of medications and treatments, including clozapine and Electroconvulsive Therapy (ECT) in 2016 with a moderate response. He has a long history of multiple prolonged hospitalizations on inpatient units.

\section{Substance use history}

$\mathrm{K}$ started experimenting with substances at age 15 and later on, he used them regularly. The substances that he used included crack-cocaine, heroin, amphetamines and inhalants. He has never received services in a rehabilitation facility or required emergency services for withdrawal symptoms.

\section{Medical history}

$\mathrm{K}$ was diagnosed with asthma at an early age and has required intermittent use of albuterol inhalant; he has never been in the Emergency Room or admitted to a medical unit because of his symptoms of asthma. He would get exacerbations of asthma once a year that resolve with Albuterol. After a couple of years receiving antipsychotics for his symptoms of psychosis and mania, K gained 30lbs, which had a significant role in his new diagnoses of obesity, diabetes mellitus type 2, and hypertension. $\mathrm{K}$ was not engaged in the treatment of these medical conditions and frequently declined medications to control them, with negative consequences such as elevated HbAlc levels and one episode of diabetic ketoacidosis mentioned in the section above.

\section{Legal history}

He was incarcerated for two months in 2014 after he physically assaulted one of his family membersand subsequently transferred to the state hospital.

\section{Social history}

$\mathrm{K}$ was born in the United States and was raised by his biological parents; he is an only child. During his early childhood, he was closer to shi father since his mother did not spend much time with their family. K's parents argued frequently but he denied witnessing or being a victim of physical or sexual violence. K's parents separated when $\mathrm{K}$ was ten years old and his paternal grandmother took care of him during those years. $\mathrm{K}$ attended his neighborhood public schools and received regular education; he denied any learning difficulties until he turned 15 years old and started presenting with the symptoms described above and started using illicit substances; K stopped attending highschool because of frequent psychiatric admissions and his difficulty to concentrate in class. $\mathrm{K}$ had a few friends, however, they were associated with the illicit use of substances. He is single, has never married, and does not have children. $\mathrm{K}$ has never worked and is supported by Social Security Disability and receives Food Stamps. K's father died suddenly when K was 22 years old, reasons for his death are unclear to $\mathrm{K}$ and these authors. 


\section{Family history}

K reported his father used to drink alcohol regularly. K's maternal uncle committed suicide when $\mathrm{K}$ was five years old and he reports he does not remember the event.

\section{Discussion}

The case presented above exemplifies the challenges that result from the intersection of severe mental illness, one's autonomy and capacity. During K's admissions to psychiatric and medical units, it became clear that he would need help to make decisions regarding his health.

It is noteworthy that no particular psychiatric or medical illness automatically leads to one's incompetence. The decision is based on a clinical capacity assessment and a judge's decision should determine competent or incompetent functioning [8]. Nevertheless, mental health issues can affect the patient's judgment and capacity and assessed as "incapable of making independent decisions." In those cases, patients might benefit from "support decision making," which is based on autonomy and provides support to people whose decision-making ability is impaired to enable them to make their own decisions whenever it is possible [9]. However, other groups of patients affected by severe mental illness cannot make judicious decisions on their own.

The medical ethics, as embodied in the American Medical Association's Code of Medical Ethics, makes clear that while the autonomy of competent individuals must be respected, irrational or otherwise impaired individuals are not considered autonomous agents [10]. As such, a surrogate decision-maker may be appointed to overrule the decisions of an incompetent patient [10]. The assessment of mental capacity can center on judicial intuition as much as on medical evidence [11]. Therefore physicians play a significant role in assessing capacity, providing advice, guidance and support to the surrogate, conservator, or judicial authorities [10]. During K's inpatient admissions to the medical and psychiatric units, communication with inpatient treaters was essential in order to provide collateral information, previous medication trials and to discuss treatment plans and disposition; the physician liaison role with other providers is fundamental in high complexity cases [12]. These issues become mainly involved in the context of TAY, where autonomy and capacity are new concepts based on their chronological age.

During the course of K's hospitalization, multiple instances occurred when his capacity might have been questioned. $\mathrm{K}$ often made decisions on his own, including all the times when he looked for help in the ER, asked for medications and treatment to help with his symptoms and agreeing to surgical drainages, or when he chose to be discharged to supportive housing instead of his extended family. Most of these decisions have a positive impact on his health. However, in other instances, $\mathrm{K}$ made decisions that had negative consequences, such as demanding for his early discharge from inpatient psychiatric units, declining to take psychiatric medications when the Consultation and Liason team recommended it, or when $\mathrm{K}$ stopped taking his medications after beings discharged to home. Moreover, in other circumstances, K's capacity was assumed and a detailed assessment was not conducted, as when he received ECT during one of his last inpatient admissions. All the situations mentioned exemplifying some of the challenges encounters when treating patients with mental health issues are essential to understand the importance of prompt assessment for capacity and to take into consideration the elements necessary to ensure the appropriate care, such as considering tools like conservatorship or guardianship.

Conservatorship or guardianship has been established in multiple states in the United States as a way of guaranteeing the best decisions for patient's health care. The goal of supervising and making health decisions for patients without capacity is to decrease relapses and help the patient reintegrate into society. Chronic illness, including mental health, in young adults, is a well-recognized cause of disability, mental health sequelae, educational and occupational limitations, and financial hardship [13].

In the case mentioned above, $\mathrm{K}$ viewed autonomy as an achievement he gained over the years and as the ability to do everything he pleased. However, the decisions he made under his autonomy were not the best for his health; some of them resulted in detrimental effects on his health, such as obesity and diabetes.

Applying, or even considering conservatorship, could be detrimental to the doctor-patient relationship. Researchers have shown definitively that the therapeutic working alliance between patient and practitioner as the single most crucial factor in the treatment of mental health [14]. However, weighing risks and benefits must always direct care to the best outcome ina patient's health.

A case series of 17 patients from a Veterans Administration Hospital highlighted the importance but circumscribed effects of being conserved. The report found evidence that having a conservator seems to improve patient's access to necessities, notably shelter; however, it did not find any effect on clinical relapses into psychosis or substance abuse [8].

Autonomy and capacity are complex topics in general, and applying them to TAY carries multifaceted challenges that will be encountered mainly during vulnerable times. These include involuntary admissions, decompensation due to medication non-adherence, and refusal to accept treatments. The paucity of research published about this topic in the TAY population makes the matter more daunting. See Table 1 for recommendations when working with TAY that suffer from severe mental illness admitted to the inpatient medical or psychiatric unit.

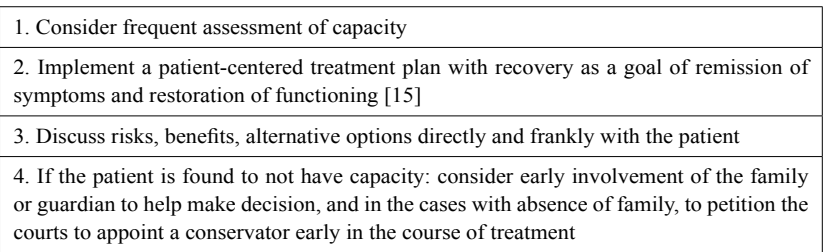

Table 1: Recommendations when treatingTAY with severe mental illness admitted to the inpatient medical or psychiatric unit.

\section{Disclosures and Acknowledgments}

The authors report no conflict of interest, financial support, or other relationship relevant to this paper. 


\section{Previous Presentation}

Authors have presented some data relevant to this paper at the American Academy of Child and Adolescent Psychiatry (AACAP) 2019 Annual Meeting.

\section{References}

1. Wilens TE, Rosenbaum JF (2013) Transitional aged youth: a new frontier in child and adolescent psychiatry. J Am Acad Child Adolesc Psychiatry 52: $887-890$.

2. de Girolamo G, Dagani J, Purcell R, Cocchi A, McGorry PD (2011) Age of onset of mental disorders and use of mental health services: needs, opportunities and obstacles. Epidemiology and Psychiatric Sciences 21: 47-57.

3. Jones PB (2013) Adult mental health disorders and their age at onset. Br J Psychiatry Suppl 54: 5-10.

4. Kessler RC, Berglund P, Demler O, Jin R, Merikangas KR, et al. (2005) Lifetime Prevalence and Age-of-Onset Distributions of DSM-IV Disorders in the National Comorbidity Survey Replication. Arch Gen Psychiatry 62: 593-602.

5. McMillen JC, Raghavan R (2009) Pediatric to adult mental health service use of young people leaving the foster care system. J Adolesc Health 44: 7-13.

6. Reiss J, Gibson R (2002) Health Care Transition: Destinations Unknown. Pediatrics 110:1307-1314
7. Lee BR, Munson MR, Ware NC, Ollie MT, Scott LDJ, et al. (2006) Experiences of and Attitudes Towards Mental Health Services Among Older Youths in Foster Care. Psychiatr Serv 57: 487-492.

8. Frank JB, Degan D (1997) Conservatorship for the Chronically Mentally Ill: Review and Case Series. Int J Law Psychiatry 20: 97-111.

9. Davidson G, Kelly B, Macdonald G, Rizzo M, Lombard L, et al. (2015) Supported decision making: A review of the international literature. Int $\mathrm{J}$ Law Psychiatry 38: 61-67.

10. AMA (2017) Code of Medical Ethics. American Medical Association, Chicago, USA.

11. Hartman B (2009) Conservatorship of Burton: Mental Illness and the Right to Refuse. J Law Med 37: 380-382.

12. Noblett J, Caffrey A, Deb T, Khan A, Lagunes-Cordoba E, et al. (2017) Liaison psychiatry professionals' views of general hospital care for patients with mental illness: The care of patients with mental illness in the general hospital setting. J Psychosom Res 95: 26-32.

13. Ewais T, Banks C (2018) Health and justice partnerships for young adults - when health and law unite in care. Health Education Journal 77: 656-666.

14. Osborn LA, Stein CH (2019) Recovery-oriented services in an inpatient setting: The role of consumers' views of therapeutic alliance and practitioner directiveness on recovery and well-being. Am J Orthopsychiatry 89: $115-123$.

15. Davidson L, Lawless MS, Leary F (2005) Concepts of recovery: competing or complementary? Curr Opin Psychiatry 18: 664-667. 


\section{Hit}

Journal of Anesthesia \& Clinical Care

Journal of Addiction \& Addictive Disorders

Advances in Microbiology Research

Advances in Industrial Biotechnology

Journal of Agronomy \& Agricultural Science

Journal of AIDS Clinical Research \& STDs

Journal of Alcoholism, Drug Abuse \& Substance Dependence

Journal of Allergy Disorders \& Therapy

Journal of Alternative, Complementary \& Integrative Medicine

Journal of Alzheimer's \& Neurodegenerative Diseases

Journal of Angiology \& Vascular Surgery

Journal of Animal Research \& Veterinary Science

Archives of Zoological Studies

Archives of Urology

Journal of Atmospheric \& Earth-Sciences

Journal of Aquaculture \& Fisheries

Journal of Biotech Research \& Biochemistry

Journal of Brain \& Neuroscience Research

Journal of Cancer Biology \& Treatment

Journal of Cardiology: Study \& Research

Journal of Cell Biology \& Cell Metabolism

Journal of Clinical Dermatology \& Therapy

Journal of Clinical Immunology \& Immunotherapy

Journal of Clinical Studies \& Medical Case Reports

Journal of Community Medicine \& Public Health Care

Current Trends: Medical \& Biological Engineering

Journal of Cytology \& Tissue Biology

Journal of Dentistry: Oral Health \& Cosmesis

Journal of Diabetes \& Metabolic Disorders

Journal of Dairy Research \& Technology

Journal of Emergency Medicine Trauma \& Surgical Care

Journal of Environmental Science: Current Research

Journal of Food Science \& Nutrition

Journal of Forensic, Legal \& Investigative Sciences

Journal of Gastroenterology \& Hepatology Research

Journal of Gerontology \& Geriatric Medicine
Journal of Genetics \& Genomic Sciences

Journal of Hematology, Blood Transfusion \& Disorders

Journal of Human Endocrinology

Journal of Hospice \& Palliative Medical Care

Journal of Internal Medicine \& Primary Healthcare

Journal of Infectious \& Non Infectious Diseases

Journal of Light \& Laser: Current Trends

Journal of Modern Chemical Sciences

Journal of Medicine: Study \& Research

Journal of Nanotechnology: Nanomedicine \& Nanobiotechnology

Journal of Neonatology \& Clinical Pediatrics

Journal of Nephrology \& Renal Therapy

Journal of Non Invasive Vascular Investigation

Journal of Nuclear Medicine, Radiology \& Radiation Therapy

Journal of Obesity \& Weight Loss

Journal of Orthopedic Research \& Physiotherapy

Journal of Otolaryngology, Head \& Neck Surgery

Journal of Protein Research \& Bioinformatics

Journal of Pathology Clinical \& Medical Research

Journal of Pharmacology, Pharmaceutics \& Pharmacovigilance

Journal of Physical Medicine, Rehabilitation \& Disabilities

Journal of Plant Science: Current Research

Journal of Psychiatry, Depression \& Anxiety

Journal of Pulmonary Medicine \& Respiratory Research

Journal of Practical \& Professional Nursing

Journal of Reproductive Medicine, Gynaecology \& Obstetrics

Journal of Stem Cells Research, Development \& Therapy

Journal of Surgery: Current Trends \& Innovations

Journal of Toxicology: Current Research

Journal of Translational Science and Research

Trends in Anatomy \& Physiology

Journal of Vaccines Research \& Vaccination

Journal of Virology \& Antivirals

Archives of Surgery and Surgical Education

Sports Medicine and Injury Care Journal

International Journal of Case Reports and Therapeutic Studies

Submit Your Manuscript: http://www.heraldopenaccess.us/Online-Submission.php 